\title{
High dose chemotherapy and syngeneic stem cell transplantation in a patient with refractory rheumatoid arthritis: poor response associated with persistence of host autoantibodies and synovial abnormalities
}

\author{
M van Oosterhout, R J Verburg, E W N Levarht, J D Moolenburgh, R M Barge, W E Fibbe, \\ J M van Laar
}

Background: Immunoablative therapy combined with haematopoietic stem cell transplantation (SCT) is a possible treatment for patients with severe rheumatoid arthritis (RA). Case report: $A$ patient with rheumatoid factor positive, progressively erosive RA, refractive to treatment, was treated with high dose cyclophosphamide, followed by reinfusion of an unmanipulated peripheral blood graft derived from her identical twin sister. The clinical response was unsatisfactory, necessitating reinstitution of treatment with disease modifying antirheumatic drugs, which was associated with persistence of host serum autoantibodies and a cellular infiltrate in synovium, notably of plasma cells.

Discussion: The effectiveness of syngeneic SCT may be critically dependent on the degree of immunoablation achieved or on the composition of the graft.

$\mathrm{H}$ igh dose immunosuppressive therapy and stem cell transplantation (SCT) has been described as an experimental treatment option for patients with refractory rheumatoid arthritis (RA). ${ }^{1}$ We describe a patient with refractory RA who was treated with high dose cyclophosphamide followed by syngeneic SCT. The lack of clinical response to this treatment was associated with persistence of synovial cellular infiltrate and of serum autoantibodies.

\section{CASE REPORT}

A 44 year old woman was diagnosed with rheumatoid factor positive $(\mathrm{RF}+)$, erosive RA at the age of 31. Despite treatment with (combinations of) disease modifying antirheumatic drugs (DMARDs), including methotrexate, sulfasalazine, gold, azathioprine, prednisone, oral cyclophosphamide, etanercept, and infliximab, smouldering disease persisted, leading to progressive joint destruction. The patient underwent multiple orthopaedic operations during the disease course. When screened for SCT she was treated with prednisone $7.5 \mathrm{mg}$ a day, methotrexate $15 \mathrm{mg}$ once weekly, and infliximab $200 \mathrm{mg}$ intravenously (IV) every 8 weeks. Ethics committee approval and informed consent were obtained from the patient and her identical twin sister.

Both sisters had identical blood groups $\left(\mathrm{A}^{+}\right.$and $\left.\mathrm{Rh}^{+}\right)$and identical HLA haplotypes. Syngeneity was confirmed by DNA testing, showing that the sizes of 15 microsatellite DNA markers were concordant. The patient tested positive for IgG antibodies against cyclic citrullinated peptide (CCP) and parvovirus B19. The donor was healthy and negative for serum IgM RF and IgG antibodies against CCP and parvovirus B19. Disease activity was assessed with the 28 joint Disease Activity Score. ${ }^{2}$ Synovial tissue was obtained by arthroscopy before transplantation and 2, 3, and 6 months after transplantation. The patient was conditioned with IV cyclophosphamide, $50 \mathrm{mg} / \mathrm{kg}$ a day during 4 days (day -5 until -2 , total dose $13.4 \mathrm{~g}$ ) and IV methylprednisolone $2 \mathrm{mg} /$ $\mathrm{kg}$ from day -5 to -1 followed by tapering doses of prednisone starting at $1 \mathrm{mg} / \mathrm{kg}$ a day. No granulocyte-colony stimulating factor (G-CSF) was administered after transplantation. Peripheral stem cells from the donor were mobilised by G-CSF (filgrastim) $10 \mu \mathrm{g} / \mathrm{kg}$ subcutaneously and collected by leukapheresis on day -1 and day 0 . An unmanipulated syngeneic graft of $182 \times 10^{9}$ leucocytes containing 53\% mononuclear cells and $769 \times 10^{6} \mathrm{CD} 34^{+}$cells was administered.

\section{RESULTS}

Before conditioning, DMARD treatment was discontinued, which resulted in a disease flare (fig 1). The conditioning regimen was well tolerated by the patient. She was discharged on day 14 without joint complaints. The nadir of neutrophils was on day $8\left(0.016 \times 10^{9} / 1\right)$. After 1 month disease activity flared accompanied by an acute phase response. Intra-articular injection with $80 \mathrm{mg}$ of methylprednisolone into the left knee was ineffective and 2 months after transplantation arthroscopic lavage of the knee including synovial biopsies was performed followed by a repeat arthroscopy 1 month later. Both synovial fluid and tissue were cultured for micro-organisms at both occasions, but the results were negative.

Prednisone was maintained at a dose of $7.5 \mathrm{mg} /$ day and methotrexate was reinstituted at incremental doses 15 weeks after the transplantation because of persistent disease activity. The patient was then readmitted because of disabling pain of her left knee caused by progressive osteoarthritis, leading to joint replacement surgery at 6 months after the transplantation. Joint radiographs 1 year after transplantation showed progression of joint erosion in hands, feet, ankles, and left elbow as well as loss of cartilage thickness in hand and feet joints and the right knee.

In the 2 years after the transplantation the patient again underwent orthopaedic operations. RF and antibodies against CCP and parvovirus B19 remained detectable during follow up. After failure of adding leflunomide, parenteral gold, and anakinra respectively to methotrexate, adalimumab was started alongside methotrexate, with a moderate response. Figure 1 shows the course of the clinical and laboratory measures.

Abbreviations: CCP, cyclic citrullinated peptide; DMARDs, disease modifying antirheumatic drugs; G-CSF, granulocyte-colony stimulating factor; IV, intravenously; RA, rheumatoid arthritis; RF, rheumatoid factor; $\mathrm{SCT}$, stem cell transplantation 

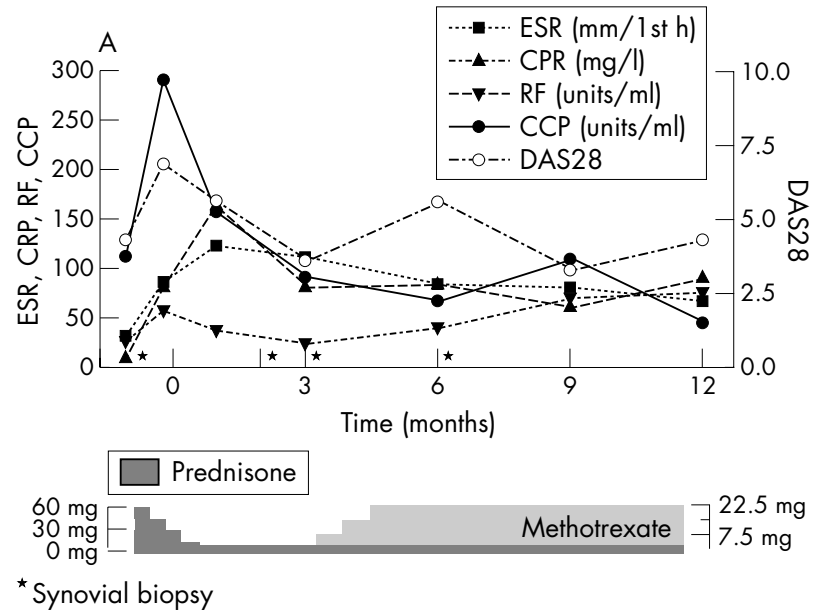

Synovial biopsy

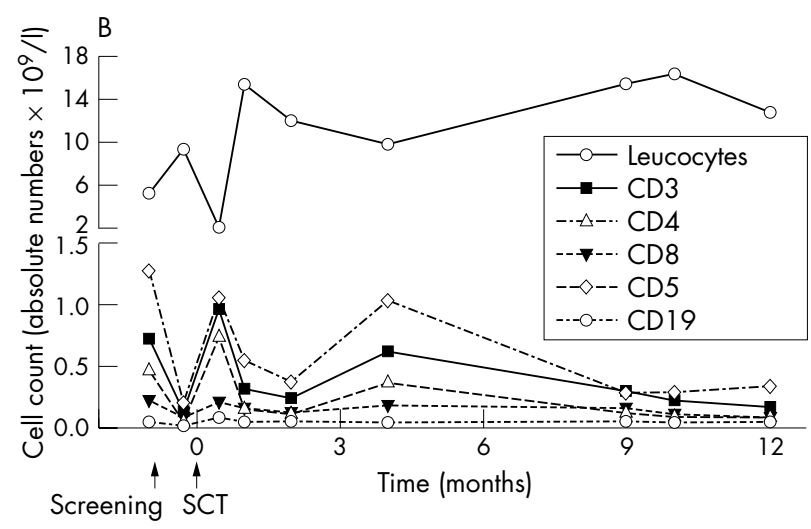

Figure 1 Clinical changes and peripheral blood leucocyte count before and after SCT. Clinical and laboratory parameters, concomitant DMARD use, and synovial biopsy time points before and after transplantation (A). Peripheral leucocyte count and mononuclear cell subset counts (flow cytometry) before and after transplantation (B).

\section{Flow cytometry and synovial tissue analysis}

Peripheral blood cell counting by flow cytometry showed a rise in mononuclear cells 2 weeks after transplantation and a reciprocal drop in total leucocyte count. After 1 month cell counts had returned to baseline values (fig 1 ). The proportion of naïve $\left(\mathrm{CD} 45 \mathrm{RA}^{+}\right.$) cells among $\mathrm{CD} 4^{+}$cells ranged from $22 \%$ to $46 \%$ during follow up (data not shown).

Synovial tissue analysis showed that a marked infiltration with neutrophils was accompanied by plasma cell infiltration on all occasions (figs 2A-D). Light chain staining excluded monoclonality of the synovial plasma cell population (not shown). Figures $2 \mathrm{E}$ and $\mathrm{F}$ show peroxidase staining of $\mathrm{CD} 3$, CD5, CD38, and CD138 after 3 months.

\section{DISCUSSION}

High dose chemotherapy followed by autologous SCT has been evaluated as a treatment option for severe RA refractory to treatment. Although promising short term results have been reported, disease relapsed in most patients. ${ }^{3}$ Of note, sensitivity to DMARD treatment seemed restored. Several causes for failure to achieve permanent remission with autologous SCT in patients with RA have been proposed. ${ }^{4}$ Based on theoretical considerations, syngeneic or allogeneic SCT might be more effective. A successful syngeneic SCT in a rheumatoid factor negative patient has been described previously, ${ }^{5}$ with evidence of donor T cell chimerism and an excellent outcome in the 7 years after treatment with cyclophosphamide, antithymocyte globulin, and syngeneic SCT (I Wicks, personal communication).

We attempted to induce remission in a patient with severe, $\mathrm{RF}+$, erosive RA by treating her with high dose chemotherapy followed by a syngeneic, unmanipulated SCT from her healthy, identical twin sister. We postulated that an unmanipulated syngeneic graft might contain regulatory $\mathrm{T}$ and B cells, while transfer of healthy stem cells would be more effective in rebuilding a non-autoaggressive immune system. Also, a previous small randomised trial showed that patients with RA treated with high dose cyclophosphamide and unmanipulated autologous SCT had fewer relapses than those who received a manipulated graft. ${ }^{6}$

The outcome in our patient was unfavourable, however. The disease course after high dose chemotherapy and syngeneic SCT was characterised by a rapid relapse of disease activity, a sustained acute phase response, and persistence of RF and anti-CCP antibodies. Several factors may have contributed to this outcome. Firstly, our patient was seropositive and after treatment RF, anti-CCP, and antiparvovirus B19 remained positive, suggesting that the host plasma cells were not eradicated by the high dose chemotherapy nor replaced by new donor derived plasma cells from the graft, which contained $<1 \% \mathrm{CD} 19^{+}$cells. This notion was supported by the persistence of plasma cell infiltration in the synovial tissue after transplantation. Secondly, because of safety concerns in a heavily pretreated patient, we opted not to use antithymocyte globulin in the conditioning regimen. Conceivably, this may have resulted in insufficient reduction of autoreactive lymphocytes. Thirdly, although the graft was enriched for mononuclear cells, granulocytes constituted a significant proportion of the graft. These cells may have been activated as a result of mobilisation with G-CSF, enabling them to home to the synovium and act as effector cells.

Because of the syngeneic setting of the transplantation, we were unable to detect chimerism after transplantation, but

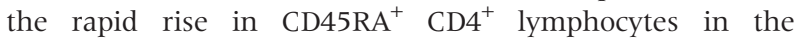
circulation within 2 weeks probably reflects a population of donor cells as this population has been shown not to recover after treatment of patients with RA with high dose cyclophosphamide. ${ }^{3}$

In conclusion, our patient was treated with high dose chemotherapy and syngeneic SCT but her disease flared after 1 month. The persistence of serum autoantibodies and marked neutrophilic and plasma cell infiltration of the synovium may have contributed to the rapid flare of RA. Preliminary data suggest transplantation of an allogeneic graft may be more effective in eradicating host immune cells than an autologous or syngeneic graft by induction of a graftversus-autoimmunity effect. ${ }^{7}$ Improved and less toxic conditioning schemes make SCTs, even allogeneic transplantations, applicable in an increasing group of patients with rheumatic diseases refractory to conventional antirheumatic drugs and biological agents.

\section{ACKNOWLEDGEMENTS}

Dr I Bajema, Department of Pathology, for providing the haematoxylin and eosin colour figures.

\section{Authors' affiliations}

M van Oosterhout, R J Verburg, E W N Levarht, J M van Laar, Department of Rheumatology, Leiden University Medical Centre, The Netherlands

J D Moolenburgh, Department of Rheumatology, Medical Centre Alkmaar, The Netherlands

R M Barge, W E Fibbe, Department of Haematology, Leiden University Medical Centre, The Netherlands 

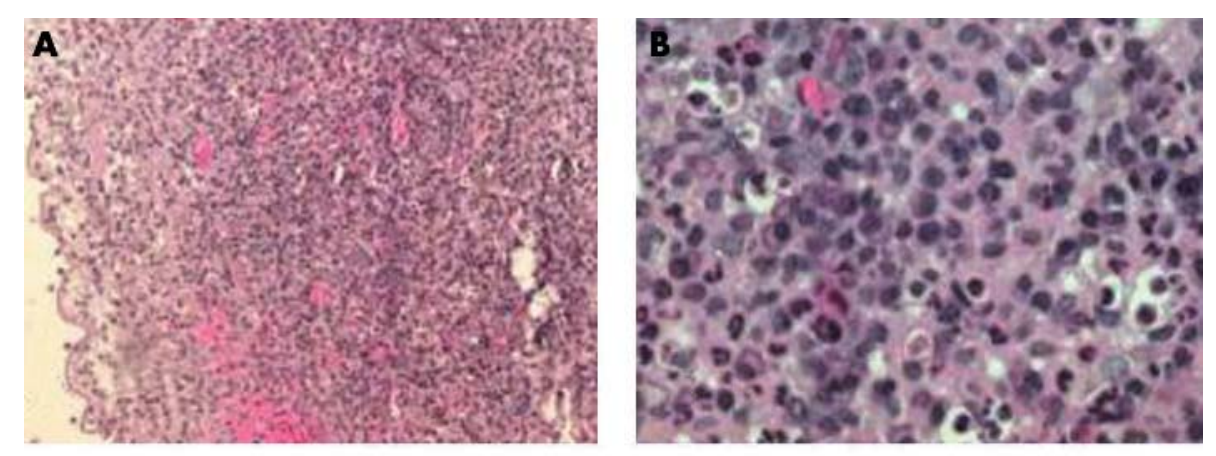

Figure 2 Haematoxylin and eosin staining $(A-D)$ at baseline ( $A$ and $B$ ) and after 2 months (C and D) showing marked infiltration of plasma cells and neutrophils. Peroxidase staining (E-H) after 2 months for CD5 (E), CD38 (F), $\mathrm{CD} 3(\mathrm{G})$, and $\mathrm{CD} 138(\mathrm{H})$. Original magnification $\times 100(\mathrm{~A}$ and $\mathrm{C}, \mathrm{E}-\mathrm{H})$ and $\times 400(B$ and $D)$.
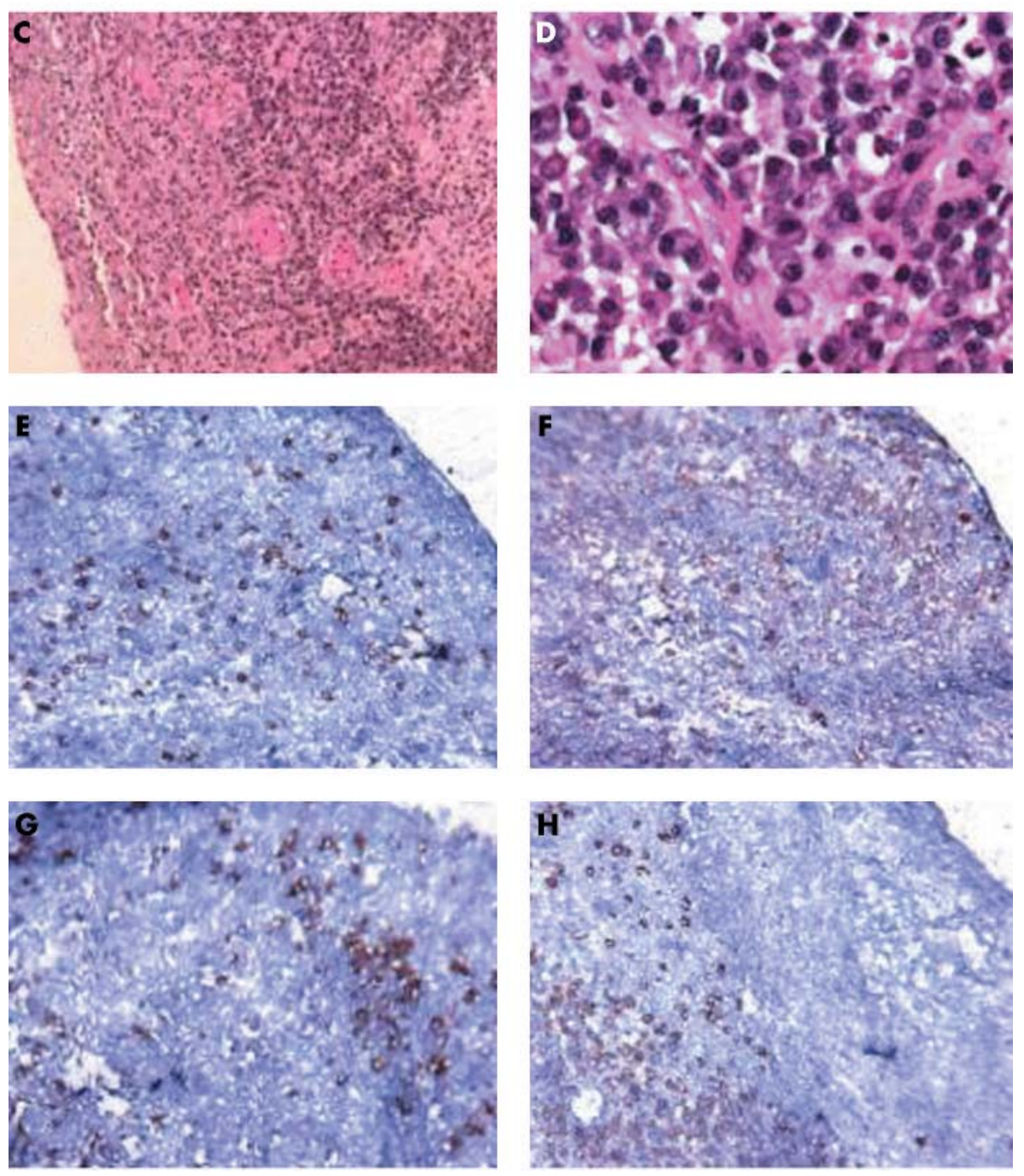

Correspondence to: Dr J M van Laar, Department of Rheumatology, Leiden University Medical Centre, PO Box 9600, 2300 RC Leiden, The Netherlands; J.M.van_Laar@LUMC.n

Accepted 14 April 2005

\section{REFERENCES}

1 Snowden JA, Passweg J, Moore JJ, Milliken S, Cannell P, Van Laar J, et al. Autologous hemopoietic stem cell transplantation in severe rheumatoid arthritis: a report from the EBMT and ABMTR. J Rheumatol 2004;31:482-8

2 Prevoo ML, van ' $t$ Hof MA, Kuper HH, van Leeuwen MA, van de Putte LB, van Riel PL. Modified disease activity scores that include twenty-eight-joint counts. Development and validation in a prospective longitudinal study of patients with rheumatoid arthritis. Arthritis Rheum 1995;38:44-8.
3 Verburg RJ, Kruize AA, van den Hoogen FH, Fibbe WE, Petersen EJ, Preijers $F$, et al. High-dose chemotherapy and autologous hematopoietic stem cell transplantation in patients with rheumatoid arthritis: results of an open study to assess feasibility, safety, and efficacy. Arthritis Rheum $2001 ; 44: 754-60$.

4 Verburg RJ, Toes RE, Fibbe WE, Breedveld FC, van Laar JM. High dose chemotherapy and autologous hematopoietic stem cell transplantation for rheumatoid arthritis: a review. Hum Immunol 2002;63:627-37.

5 McColl G, Kohsaka H, Szer J, Wicks I. High-dose chemotherapy and syngeneic hemopoietic stem-cell transplantation for severe, seronegative rheumatoid arthritis. Ann Intern Med 1999:131:507-9.

6 Moore J, Brooks P, Milliken S, Biggs J, Ma D, Handel M, et al. A pilot randomized trial comparing $C D 34$-selected versus unmanipulated hemopoietic stem cell transplantation for severe, refractory rheumatoid arthritis. Arthritis Rheum 2002;46:2301-9.

7 Burt RK, Oyama Y, Verda L, Quigley K, Brush M, Yaung K, et al. Induction of remission of severe and refractory rheumatoid arthritis by allogeneic mixed chimerism. Arthritis Rheum 2004;50:2466-70. 